*Doutorando em Direitos Coletivos e Cidadania pela Universidade de Ribeirão Preto Professor de cursos de graduação e de pós-graduação do Centro Universitário da Fundação Educacional de Barretos e do Centro Universitário Estácio de Ribeirão Preto

E-mail: dhnunes@hotmail.com

**Doutorando em Direitos Coletivos e Cidadania pela Universidade de Ribeirão Preto Professor na Universidade Paulista e na Universidade de Ribeirão Preto

E-mail: carlosmontes3@hotmail. com

*** Doutor em Direito do Estado pela Pontifícia Universidade Católica de São Paulo

Professor Titular do Programa de Doutorado, Mestrado em Direito e graduação da Universidade de Ribeirão Preto

E-mail: olavoaferreira@hotmail. com

\section{A UTILIZAÇÃO DA ARBITRAGEM PARA OS CONTRATOS DE INVESTIMENTO NO BRASIL: VANTAGENS EM RELAÇÃO AO PROCEDIMENTO JUDICIAL}

\author{
THE USE OF ARBITRATION FOR INVESTMENT \\ CONTRACTS IN BRAZIL: ADVANTAGES OVER THE \\ JUDICIAL PROCEDURE
}

\section{Danilo Henrique Nunes* Carlos Eduardo Montes Netto** Olavo Augusto Vianna Alves Ferreira***}

Como citar: NUNES, Danilo Henrique; MONTES NETTO, Carlos Eduardo Montes; FERREIRA, Olavo Augusto Vianna Alves. A utilização da arbitragem para os contratos de investimento no brasil: vantagens em relação ao procedimento judicial. Scientia luris, Londrina, v. 25, n. 3, p. 71-91, nov. 2021. DOI: 10.5433/21788189.2021v25n3p71. ISSN: 2178-8189.

Resumo: Nos últimos tempos, tem-se observado expressivo aumento no número de investidores e de dinheiro investido em aplicações financeiras ao redor do mundo, inclusive no Brasil, justificando o estudo da arbitragem como forma adequada de resolução dos conflitos que irão surgir, considerando que a justiça estatal sempre foi alvo de críticas, especialmente pela demora na solução dos casos que lhe são submetidos, o que pode gerar um ambiente de insegurança para a atração de novos investimentos. Neste sentido, o presente artigo tem por objeto analisar as vantagens da arbitragem como forma adequada de resolução de controvérsias envolvendo investimentos em comparação com a justiça estatal. Buscando alcançar esse objetivo, realizou-se uma revisão de literatura e um levantamento de dados envolvendo os fenômenos relacionados ao tema, utilizando-se do método hipotético-dedutivo. Ao final, os resultados apontaram que a arbitragem constitui um mecanismo mais adequado para a efetivação dos direitos dos investidores, apresentando-se como mais benéfica do que o processo judicial.

Palavras-chave: Vantagens da arbitragem. Investimentos. Solução de controvérsias. 
Abstract: Recently, there has been a significant increase in the number of investors and in money invested in financial investments around the world, including in Brazil, justifying the study of arbitration as an adequate way to solve the conflicts that will occur, considering that justice always the status was criticized, especially due to the delay in solving the cases, which can create an environment of insecurity for attracting new investments. In this sense, this article aims to analyze the possible advantages of using arbitration as an appropriate form of dispute resolution in comparison with state justice. Seeking to achieve this goal, a literature review and a data survey involving the phenomena related to the topic were carried out, using the hypothetical-deductive method. In the end, the results showed that arbitration is a more adequate mechanism for the realization of investors' rights, presenting itself as more beneficial than the judicial process.

Keywords: Advantages of arbitration. Investments. Dispute resolution. 


\section{INTRODUÇÃO}

No plano internacional, a globalização modificou as relações entre os Estados, alterando ainda, de maneira substancial, a dinâmica dos investimentos estrangeiros. No passado, era comum apenas os Estados desenvolvidos remeterem capital para os Estados em desenvolvimento ou subdesenvolvidos. Nos dias atuais, passou-se a observar a presença de outros atores nesse segmento, com o ingresso de particulares, bancos e empresas como provedores de capital para investimento e também um fluxo de capital no sentido inverso, já que os Estados importadores de capital também possuem empresas e investidores privados extremamente capitalizados e com ânimo para investir em outros territórios (HERNANDES NETO, 2011, p. 6).

Tornaram-se frequentes notícias de investidores que perderam seu patrimônio em países estrangeiros em razão de medidas arbitrárias e hostis ao capital estrangeiro, gerando desconfiança por parte dos investidores e dos países exportadores de capital (GIUSTI; TRINDADE, 2005). Ao verem seus investimentos desapropriados pelos governos de países que receberam tais recursos, os investidores vivenciavam uma situação de impotência, em que não dispunham de instrumentos eficientes para reaver o que perderam (GIUSTI; TRINDADE, 2005). Nesse cenário, as partes dispunham apenas da proteção diplomática ou dos tribunais nacionais para solucionar os seus conflitos (HERNANDES NETO, 2011, p. 6).

A proteção diplomática se revelava deficiente (sujeitando-se ao arbítrio dos governantes) e a judicial esbarrava em grandes entraves, como questionamentos sobre a neutralidade do foro, sobretudo se o foro escolhido fosse o do local do investimento, com a possibilidade de os tribunais estarem sujeitos a pressões políticas. Caso se optasse pelo foro de um terceiro Estado (neutro), dificilmente a decisão seria executada voluntariamente pela parte sucumbente e a decisão poderia representar apenas uma vitória moral (GIUSTI; TRINDADE, 2005).

Como os mecanismos de proteção aos investimentos não ofereciam segurança razoável, evidenciou-se a necessidade de um foro no qual investidores e Estados pudessem resolver suas avenças, surgindo o Centro Internacional de Resolução de Disputas sobre Investimentos (International Centre for Settlement of Investment Disputes - ICSID), entidade vinculada ao Banco Mundial (GIUSTI; TRINDADE, 2005).

Por intermédio do ICSID, os investidores passaram a contar com uma instituição especializada na solução de controvérsias relacionadas a investimentos estrangeiros, com acesso ao Estado receptor, deixando os investidores de depender dos seus Estados de origem para reclamar eventual expropriação (HERNANDES NETO, 2011, p. 6). No entanto, por questões que transcendem aos contornos do presente estudo, o Brasil não subscreveu a Convenção de Washington.

No âmbito interno, segundo pesquisa realizada pela Associação Brasileira das Entidades dos Mercados Financeiro e de Capitais (Anbima), o volume aplicado por pessoas físicas em produtos financeiros aumentou 8,4\% em 2019 e alcançou R \$ 3,1 trilhões no mês de setembro, representando a soma de mais de 79 milhões de contas dos segmentos de varejo e de "private 
banking” das instituições financeiras (COTIAS, 2019).

Nesse contexto, a arbitragem surge como uma opção nos conflitos que envolvem investimentos estrangeiros ou nacionais que possuam matérias complexas sobre as quais os juízes geralmente não têm conhecimento específico (CRACKEN, 2014, p. 127). Apesar de se tratar de uma das formas mais antigas de solução de conflitos pela heterocomposição no mundo, no contexto nacional, apenas em 1996 a arbitragem se apresentou como uma das mais importantes modalidades de solução de conflitos patrimoniais.

Antes da entrada em vigor da Lei 9.307, de 23 de setembro de 1996, o instituto não era muito utilizado, considerando que o Código de Processo Civil de 1973 determinava a homologação do chamado "laudo arbitral", por meio de sentença judicial, com a possibilidade de interposição de recursos, convertendo o Poder Judiciário em uma espécie de segunda instância da arbitragem.

Até o final do século passado, o Brasil não cogitou firmar acordos ou tratados de proteção do investimento estrangeiro, em razão de o nosso direito ter dificultado a homologação de sentenças arbitrais estrangeiras e deixado de incentivar a arbitragem no país. De acordo com Arnoldo Wald (2009) isso constituiu uma das últimas "ilhas de resistência" ao movimento mundial favorável às soluções de conflitos pelo uso da arbitragem".

O nacionalismo que dominou a política brasileira, em especial durante o Estado Novo e em período posterior não via com simpatia a execução, no Brasil, de decisões proferidas no exterior. Naquela época, o Brasil não participava muito do comércio mundial, limitando-se a exportar commodities e a importar equipamentos e artigos de consumo. No caso de conflitos, buscavam-se soluções conciliatórias baseadas nos próprios interesses das partes de continuar a comercializar os seus produtos.

Dentro desse contexto, a cultura jurídica brasileira ainda admitia a equiparação da decisão arbitral à sentença judicial. Observava-se no Brasil uma postura até mais reservada em relação à arbitragem do que com relação aos demais países latino-americanos, que em sua maioria aderiram à Convenção de Washington, antes que o Brasil cogitasse sua adesão (WALD, 2009). Entretanto, na última década do século passado, com o ganho de força do movimento de privatização e de abertura da economia brasileira aos investimentos estrangeiros, a arbitragem brasileira e internacional começou a consolidar a sua posição. O surgimento de uma nova legislação e a evolução da jurisprudência e da doutrina ensejaram uma "revolução cultural" na matéria, aumentando exponencialmente a procura pela arbitragem (WALD, 2009).

Em consequência do sucesso da arbitragem comercial, cada vez mais áreas do direito incorporaram o uso da arbitragem, inclusive na resolução de disputas coletivas, a exemplo do art. $114, \S 2^{\circ}$, da CF que trata da possibilidade da utilização da arbitragem nos dissídios trabalhistas coletivos, da previsão de uso da arbitragem na Lei de Greve - arts. $3^{\circ}$ e $7^{\circ}$ da Lei $n^{\circ} 7.783 / 89$ - e da mediação e da arbitragem de oferta finais na Lei de Participação nos Lucros - art. $4^{\circ}$, II da Lei no 10.101/00 - (FERREIRA; ROCHA; FERREIRA, 2019, p. 99).

Existem notícias de que um grupo de investidores minoritários estava tentando viabilizar uma arbitragem coletiva em desfavor da Petrobrás, com o objetivo de obterem ressarcimento das 
perdas apuradas com a desvalorização das ações da companhia em decorrência da operação LavaJato da Polícia Federal, responsável por investigar supostos pagamentos de propina pela empresa (FERREIRA; ROCHA; FERREIRA, 2019, p. 99). Destarte, observa-se que não deve o setor de investimentos abrir mão de um instrumento tão adequado, especializado e célere para a resolução das suas disputas.

Assim, a pesquisa se justifica pela necessidade de analisar se a arbitragem pode se revelar vantajosa enquanto método adequado de solução de disputas que versam sobre contratos de investimentos, em comparação com a Justiça estatal, como forma de acesso à justiça, diante da escassez de estudos específicos sobre o tema.

Buscando alcançar o objetivo pretendido de acordo com uma análise qualitativa do contexto, para este estudo optou-se pela realização de uma pesquisa exploratória, por meio de revisão bibliográfica, com ênfase nas dimensões doutrinária, normativa e jurisprudencial que envolvem a interpretação de normas infraconstitucionais, valendo-se da análise de julgados do Superior Tribunal de Justiça (STJ) e de outros Tribunais, de trabalhos acadêmicos, livros e artigos científicos, empregando-se o método hipotético-dedutivo.

\section{ASPECTOS CONCEITUAIS DE ARBITRAGEM}

A celeridade na prestação jurisdicional ainda constitui um dos maiores desafios do Judiciário, mesmo após a Emenda Constitucional n. 45/04, que incluiu a "duração razoável do processo" e a "celeridade de sua tramitação" no rol do art. $5^{\circ}$, da $\mathrm{CF}$, lembrando que "justiça atrasada não é justiça, senão injustiça qualificada e manifesta", de acordo com a lição de Rui Barbosa (1997).

Conforme destaca José Renato Nalini (2018, p. 29), o Brasil fornece ao mundo uma visão de que aqui se vivencia uma guerra de todos contra todos, evidenciando que a vocação humana seria o eterno litígio, considerando que uma população de 202 milhões de habitantes apresenta mais de 100 milhões de processos judiciais, passando a ideia de que toda a nação estivesse a demandar. Nesse contexto de necessidade de se buscar mecanismos mais céleres do que o Judiciário, o processo civil vem se modificando radicalmente e a justiça estatal adjudicada já não é mais o único instrumento adequado para a resolução de conflitos (DIDIER JÚNIOR; ZANETI JÚNIOR, 2018, p. 38). Sustenta-se, atualmente, que ao lado desta justiça de porta única surgiram novas formas de acesso, tornando a justiça multiportas (DIDIER JÚNIOR; ZANETI JÚNIOR, 2018, p. 38).

Uma dessas portas de acesso à justiça é a arbitragem, que na lição de Alexandre Freitas Câmara (1997), constitui um meio paraestatal de solução de conflitos, por meio da heterocomposição, que pode ser conceituada como uma técnica para solucionar disputas com a intervenção de uma ou mais pessoas que receberam poderes de uma convenção privada e que decidem com base nessa convenção, sem intervenção estatal, assumindo a decisão eficácia de sentença judicial. A arbitragem, assim, constitui ainda um método vantajoso de resolução de disputas em comparação 
ao processo estatal, em especial com relação à celeridade, confidencialidade, flexibilidade de procedimento e especialização dos julgadores (CREMASCO; BENTO; FIORAVANTE, 2018, p. 856), além de adequado, considerando que não existe superioridade da justiça estatal com relação aos outros meios de solução de conflitos (DIDIER JÚNIOR; ZANETI JÚNIOR, 2018, p. 39).

Em razão disso, o Ministro Luis Felipe Salomão (2014) assentou que a arbitragem representa um avanço do processo civilizatório da humanidade, que passa a ter a possibilidade de buscar, conscientemente, mecanismos de pacificação social mais eficientes do que a assoberbada jurisdição estatal. Com relação à duração, o prazo para a sentença arbitral ser proferida é de seis meses, caso não tenha sido outro convencionado pelas partes (nos termos do art. 23 da Lei de Arbitragem), contados da instituição da arbitragem ou da substituição do árbitro. Já os processos judiciais, de acordo com dados do Conselho Nacional de Justiça, aguardam em média por solução 4 anos e 10 meses (CONSELHO NACIONAL DE JUSTIÇA, 2019), sem levar em conta o prazo para julgamento de eventuais recursos interpostos até os Tribunais Superiores, que podem alongar a espera.

\section{DOS INVESTIMENTOS E A ARBITRABILIDADE DE EVENTUAIS DISPUTAS SURGIDAS ENTRE OS INVESTIDORES}

Cada vez mais os Estados e os particulares têm se empenhado na captação de investimentos com a finalidade de alavancar o seu desenvolvimento, promovendo direta ou indiretamente o bemestar social dos indivíduos e contribuindo para a efetivação dos direitos e garantias fundamentais previstos na Constituição da República Federativa do Brasil de 1988 (BRASIL, 1988) ${ }^{1}$, sendo o Brasil, de acordo com ranking elaborado no ano de 2020 pela consultoria norte-americana A.T. Kearney, o $22^{\circ}$ país que mais atraiu investimentos estrangeiros (VILELA, 2020).

Esses investimentos, por sua vez, podem ser classificados em diversas espécies tais como diretos ou indiretos, nacionais ou estrangeiros, dentre outras que ultrapassam os limites da presente pesquisa, ou, ainda, decorrer de relações entre particulares, entre particulares e o Estado ou mesmo entre Estados.

$\mathrm{O}$ investimento direto corresponde ao investimento em dinheiro em um projeto ou empresa, proporcionando ao investidor o direito de participar ativamente da gestão da empresa, capacitando-o a influenciar nas decisões que serão tomadas pelos seus dirigentes, abrangendo o investimento de capital em um objeto de investimento específico, como a aquisição de ativos reais (aquisição de equipamentos ou edifícios, por exemplo) ou o investimento de capital em fundos estatutários de organizações (SPMOST, 2021).

Já os investimentos de portfólio, também denominados "indiretos", envolvem o investimento de capital do investidor em objetos de investimento realizados por intermediários

$1 \mathrm{O}$ bem-estar das pessoas nas sociedades modernas apresenta relação direta com o volume e a qualidade dos bens de consumo que são adquiridos de acordo com a renda que pode se originar do trabalho ou de transferências privadas ou públicas (GUIMARÃES, 2000). 
financeiros representados, em regra, por títulos, bancos de depósitos ou moeda estrangeira, sendo o investidor de portfólio o indivíduo que adquiriu um instrumento financeiro visando a formação de uma "carteira de investimentos" (BANK, [s.d.]).

O capital investido pode ainda ser classificado em nacional ou estrangeiro, dependendo da sua origem. Corrêa (2007, p. 07) conceitua o Investimento Direto Estrangeiro (IDE) como um "subproduto da inciativa de crescimento da firma, através da criação de subsidiárias e filiais em outros Estados", classificando-se essas firmas em Empresas Transnacionais (ETNs), que executam "operações importantes, sob orientação centralizada em território de duas ou mais nações" (CARVALHO, 1982, p. 13) e Empresas Multinacionais (EMNs), que envolvem a participação significativa nas suas operações de pessoas de duas ou mais nacionalidades (CARVALHO, 1982).

Guimarães (2000), destaca o papel dos investimentos nacionais e estrangeiros em países em desenvolvimento com o Brasil na poupança e formação de capital, apontando que enquanto o investidor nacional, em regra, busca oportunidades de investimento mais seguras e com retorno mais rápido, o investimento estrangeiro permitiria o aumento total da poupança disponível para investir, com a possibilidade de promover a aceleração do desenvolvimento nacional com menor sacrifício e obstáculos políticos não apenas para a população, mas também para as elites econômicas.

No que se refere à utilização da arbitragem internacional na resolução de disputas entre investidores e o Estado, Costa (2006) salienta que a adoção dessa via adequada tem ganhado destaque, diante da necessidade de proteção da iniciativa privada e da sua finalidade lucrativa.

Nesse contexto, verifica-se um conflito entre os interesses dos investidores particulares e dos Estados que hospedam esses investimentos, com aqueles, de um lado, buscando a segurança e a proteção dos seus investimentos e esses últimos, que apesar de necessitarem e desejarem o capital externo, visam zelar pela sua soberania, especialmente no que diz respeito às suas riquezas e recursos naturais (COSTA, 2006).

A propósito, conforme já mencionado, em 1965 foi criado o ICSID, pela Convenção de Washington, que passou a permitir o acesso direto dos investidores particulares a um tribunal arbitral internacional em desfavor de um Estado que pode renunciar às suas prerrogativas jurisdicionais e se submeter a esse foro, como forma de mitigação da sua soberania estatal.

Um exemplo prático da possibilidade de se recorrer ao ICSID é representado pelas controvérsias entre a Bolívia e um grupo de investidores estrangeiros que inclui a Petrobras, considerando que a Bolívia aderiu à Convenção de Washington, abrindo a possibilidade de utilização desse tribunal arbitral para a resolução da disputa envolvendo a nacionalização de hidrocarbonetos efetivada pela Bolívia no dia $1^{\circ}$ de maio de 2006.

No entanto, o Brasil permanece afastado desse instrumento internacional especializado na resolução de controvérsias sobre investimentos estrangeiros, o que pode representar, em tese, obstáculo para a ampliação da presença do capital estrangeiro e dificultar o crescimento econômico e social do país, mas não impede a adoção da via arbitral para a resolução de conflitos envolvendo investimentos estrangeiros, se as partes assim desejarem.

No que interessa ao presente estudo, destaca-se que é possível a eleição da arbitragem 
para a resolução de qualquer conflito decorrente de contrato de investimentos, desde que envolvam partes maiores e capazes, denominada arbitrabilidade subjetiva, nas relações estabelecidas entre particulares, entre particulares e o Estado ou mesmo entre Estados, qualquer que seja o tipo de investimento realizado no Brasil (direto ou indireto, nacional ou estrangeiro).

Quando o contrato envolver os entes estatais internos, observa-se que o art. $1^{\mathrm{o}}, \S 1$, da Lei de Arbitragem, com a redação conferia pela Lei n 13.129/15, incluiu a Administração Pública direta e indireta no rol dos capazes de contratar a arbitragem. Em reforço, a Lei $n^{\circ} 14.133$, de $1^{\circ}$ de abril de 2021 (BRASIL, 2021), denominada "Lei de Licitações e Contratos Administrativos", também prevê no seu art. 151 que a Administração Pública poderá utilizar "meios alternativos" na resolução de disputas envolvendo seus contratos, podendo a arbitragem ser eleita, inclusive, por meio de aditamento contratual (art. 153).

Destarte, observa-se a ampla possibilidade de utilização da via arbitral para a resolução de disputas envolvendo contratos de investimentos realizados no Brasil, devendo a análise da utilização da arbitragem em cada tipo de investimento específico ser objeto de novos trabalhos que ultrapassam os limites da presente pesquisa.

\section{DAS VANTAGENS DA ARBITRAGEM NO ATENDIMENTO À GARANTIA CONSTITUCIONAL DA RAZOÁVEL DURAÇÃO DO PROCESSO}

Dentre as vantagens que a arbitragem proporciona, enumera-se a título exemplificativo:

i) Celeridade: constitui vantagem muito importante da arbitragem, comparada com o processo judicial ${ }^{2-3-4-5-6}$ é nítido o fato de que a arbitragem é muito mais célere, já que o art. 23 da Lei de Arbitragem estabelece que o procedimento arbitral deve terminar após seis meses, contados da instituição da arbitragem ou da substituição do árbitro, desde que não haja disposição em contrário ${ }^{7}$.

$\overline{2 \text { No ano de } 2014}$ a morosidade processual foi a principal reclamação recebida pela Ouvidoria do Conselho Nacional de Justiça (MONTENEGRO, 2014).

3 Novamente, entre janeiro e novembro de 2015, mais da metade das demandas para a Ouvidoria do CNJ tiveram como objeto a morosidade processual (FERNANDES, 2015).

4 O Judiciário brasileiro terminou o ano de 2016 com 79,7 milhões de processos em tramitação (CONSELHO NACIONAL DE JUSTIÇA, 2017).

5 Segundo notícia veiculada pelo CNJ, em 2017, apesar dos esforços do Judiciário, o Brasil ainda tinha mais de 80 milhões de processos pendentes de julgamento (MONTENEGRO, 2017).

6 O estoque de processos pendentes ao final de 2018, no Judiciário brasileiro, foi de 78.691 .031 ações, o que representa queda de apenas $1,2 \%$ em relação a 2017 (CNJ, 2019).

7 Há arbitragens complexas que as partes convencionam dilatar o prazo, diante da instrução com grandes perícias e outras provas a serem produzidas, mas não há fase recursal na arbitragem, a qual é presente no processo judicial acarretando na demora em vários anos até o esgotamento dos recursos. Recente pesquisa ilustra a rapidez do processo arbitral: "para um conjunto de 42 arbitragens, cinco foram concluídas em menos de um ano e 27 em menos de dois anos. Nesse universo, cinco procedimentos consumiram mais de dois anos e quatro excederam três anos. Há somente um caso extremo no qual a sentença exigiu um tempo de quatro anos" (CHACEL; LOSS, 2017, p. 35). Sobre o prazo convém citar a recomendação de Joaquim Muniz: "Deve-se tomar cuidado para não se estabelecer prazo muito curto para a arbitragem, pois o eventual litígio, dependendo de sua complexidade, pode demandar mais tempo do que o previsto para ser resolvido. E, uma vez fixado o prazo para a prolação da sentença, ele deve ser seguido, salvo se as regras permitirem prorrogação. O desrespeito ao prazo implica possibilidade de anulação de sentença" (MUNIZ, 
Segundo o Conselho Nacional de Justiça, a duração de média de um processo é de quatro anos e dez meses (CONSELHO NACIONAL DE JUSTIÇA, 2019), sem contar o prazo para julgamento dos recursos até os Tribunais Superiores, impossível de ser calculado previamente ${ }^{8}$. Mesmo em questões complexas é possível verificar a celeridade dos procedimentos arbitrais, tendo em vista que estimativas realizadas entre as instituições de arbitragem demonstram que, nos casos com maior dificuldade, os prazos, em média, para encerramento do procedimento, é de um pouco mais de um ano ${ }^{9}$. Salienta-se que a sentença arbitral não admite recurso para outras instâncias, o que contribui com a celeridade abordada.

Importante citar que os usuários das arbitragens, em regra, estão satisfeitos com a celeridade do processo arbitra $1^{10}$. Ressalta-se que o árbitro tratará do caso individual com prioridade, diferente de uma vara judicial estatal ${ }^{11}$, já que esta receberá mais um caso dentre uma pletora, que não terá tramitação célere tanto quanto a parte espera, diante das dificuldades que o Judiciário ${ }^{12-13}$ sofre com estrutura, ante a escassez de recursos financeiros. Enquanto a instituição arbitral tem estrutura melhor do que a vara judicial, além de cumprir prazos de tramitação, inclusive prazo para a prolação de sentença, sob pena de nulidade (art. 32, VI da Lei de Arbitragem).

Em seguida, ii) Forma de tratamento da lide: é possível verificar que a arbitragem oferece um tratamento mais dedicado e com melhor estrutura, quando comparado ao Poder Judiciário, que com imensurável volume de trabalho, não consegue, muitas vezes, analisar cada caso individual com a devida cautela. Além disso, casos concretos complexos, que exigem um profundo conhecimento de matérias específicas pode ser solucionado de maneira mais adequada por um árbitro ou tribunal arbitral, escolhidos pelas partes, que conheçam da matéria de forma profunda.

Mesmo sentido, iii) Escolha do árbitro especializado: a possibilidade de escolha do Julgador, segundo Cahali (2017, p. 120), é uma das mais reconhecidas vantagens da Arbitragem, no momento em que as partes podem realizar suas escolhas a partir de importantes critérios como

2016). Há casos excepcionais que a arbitragem demorou quatro anos só para a constituição do tribunal arbitral, diante de sucessivos incidentes de suspeição dos árbitros, certo que a sentença demorou mais quatro anos, num total de oito anos (BRASIL, 2018b).

8 No dia 06/12/2018 a Quarta Turma do STJ decidiu que o Palácio Guanabara, sede do governo do Rio de Janeiro, é de domínio da União, não sendo devida indenização à antiga família imperial, que também não tem direito de posse sobre o imóvel. Por ocasião desse julgamento, o processo estava em tramitação há 123 anos. O feito chegou a ser extinto na década de 1960, mas continuou a tramitar em razão da interposição de recursos. Em 2018, os recursos foram incluídos em pauta e o julgamento foi adiado ao menos três vezes. Ainda havia a possibilidade de interposição de recursos contra essa decisão proferida pelo STJ (PONTES, 2018).

9 Há notícias de casos excepcionais com perícias complexas que a arbitragem tem duração maior, mediante convenção das partes, mas são excepcionais, aproximadamente "dois a três anos em litígios muito complexos" (MUNIZ, 2016).

10 Conforme pesquisa CBAr-Ipsos (ABBUD, 2012).

11 Em 2017 cada juiz julgou quase oito casos em média por dia útil, segundo o Conselho Nacional de Justiça (CNJ, 2019).

12 “A ineficiência das cortes estatais será um incentivo para que o indivíduo resolva suas disputas alterando seus padrões negociais, de forma a evitar ou tornar desnecessária a disputa judicial” (SALAMA, 2012, p. 388).

13 Em 2018 o STJ condenou o Estado do Amazonas ao pagamento de indenização por retardo na prestação jurisdicional, em razão da deficiência no serviço estatal. A parte ajuizou ação de execução de alimentos em 02/11/2004 e apenas em 03/05/2007 foi proferido do despacho citatório (BRASIL, 2018a). 
confiança e conhecimento específico sobre a matéria ${ }^{14}$, no caso agronegócios.

Assim, complementando os apontamentos, iv) Flexibilidade procedimental: a flexibilidade é outra vantagem muito importante na arbitragem, "no qual deve prevalecer, em regra, a autonomia da vontade" 15 . Enquanto no âmbito do procedimento judicial estatal a legislação processual é taxativa, não havendo como regra possibilidade de livre modificação do procedimento, embora os negócios jurídicos processuais, como exceção, estejam cada vez mais se desenvolvendo (art. 190 do CPC/2015), no procedimento arbitral, temos o privilégio da flexibilidade e da autonomia da vontade das partes que, a partir da convenção de arbitragem, podem definir, detalhadamente, como será o procedimento de arbitragem $\left(\operatorname{arts.} 2^{\circ}, \S 1^{\circ}, 11, \mathrm{IV}, 19\right.$, parágrafo primeiro e 21 caput e $\S \S 1^{\circ}$ e $2^{\circ}$ da Lei de Arbitragem $)^{16}$. É possível, inclusive, adotar-se, mediante convenção das partes, diversas informalidades para que seja resolvido o conflito da forma mais adequada possível ${ }^{17}$, desde que não ocorra ofensa à ordem pública ${ }^{18}{ }^{19}$ ou às hipóteses que ensejarão as nulidades passíveis de ação anulatória (LEMES, 1992). Segundo Gary Born (2009, p. 84) a possibilidade de adoção de procedimentos flexíveis pelas partes constitui uma das principais atrações da arbitragem comercial internacional.

No escólio de Roberto Nussinkis Mac Cracken (2014, p. 119-120) a flexibilidade do procedimento arbitral serve de atrativo para o investidor estrangeiro no Brasil, possibilitando a fuga das normas procedimentais fixadas no Código de Processo Civil brasileiro, que estabelecem prazos legais obrigatórios longos e que não necessariamente combinam com o conflito em apreço

14 "A possibilidade de melhora na qualidade das decisões, decorrente da especialização dos árbitros, também pode representar economia para as partes. Uma das vantagens da arbitragem é a possibilidade de utilização de árbitros que tenham familiaridade com a matéria objeto da controvérsia. Ao contrário do juiz estatal, o árbitro pode ter formação específica em área técnica que interessa diretamente ao objeto da arbitragem. E razoável supor, por exemplo, que o árbitro com anos de experiência na indústria petrolífera possa aferir com maior precisão os termos técnicos da contratação para exploração ou transporte de petróleo, além dos usos e costumes nos negócios da indústria petrolífera. A expectativa de que os contratos sejam interpretados por especialistas diminui os custos das partes relativos à negociação de contratos. A especialização permite, assim, a redução dos erros nas decisões arbitrais. Em tese, apesar de todos os procedimentos estarem sujeitos a erros, a probabilidade de o árbitro especializado decidir de forma equivocada, por não conhecer a matéria discutida, é menor. A redução da probabilidade de erro na decisão reduz o risco da relação contratual, tornando o contrato mais atrativo para as partes e todo o mercado" (PUGLIESE; SALAMA, 2008, p. 20).

15

(BRASIL, 2017b).

16 De maneira diversa do que ocorre nos Tribunais, o procedimento arbitral pode ser moldado às demandas específicas do conflito (LEW; MISTELIS; KRÖLL, 2003, p. 5).

17 Francisco José Cahali (2017, p. 115) leciona: "Preenchidos os pressupostos para sua escolha (capacidade de contratar a respeito de direito patrimonial disponível), é prestigiada a vontade das partes na arbitragem em seu grau máximo: começa com a liberdade para a indicação da arbitragem como forma de solução do litígio; e, prossegue, com a faculdade de indicarem todas as questões que gravitam em torno desta opção. Assim, estabelecem quem e quantos será(ão) o(s) árbitro(s), de forma direta ou indireta, e como será desenvolvido o procedimento arbitral (por exemplo, relativamente a prazos, locais para a prática dos atos, eventual restrição para apreciação de medidas de urgência ou tutelas antecipadas sem ouvir a parte contrária etc.).”

18 José Maria Roca Martínez (1992, p. 166) aponta que os árbitros têm o dever de proferir suas decisões de acordo com o ordenamento jurídico e, por óbvio, precisam observar a Constituição, inclusive na arbitragem por equidade.

19 Para Marcelo José Magalhães Bonizzi e Olavo Augusto Vianna Alves Ferreira (2017), o controle de constitucionalidade do ato constitui matéria de ordem pública, impondo-se o dever de realizar o controle difuso de ofício e não se admitindo a desistência da ação direta de inconstitucionalidade. Assim, violar uma norma constitucional significa violar a ordem pública, já que é na Constituição que se encontram os princípios e regras mais importantes do ordenamento jurídico. 
Adiante, tem-se v) Possibilidade de confidencialidade: pode ser considerada como importante vantagem da arbitragem, quando eleita pelas partes, já que não obrigatória, diante da inexistência de previsão legal nesse sentido, viabilizando que o segredo do negócio seja preservado, em casos de transferência de tecnologia, problemas técnicos de produtos, dentre outros. Enquanto o processo judicial, em regra, é público, o processo arbitral pode ser sigiloso, por força da convenção de arbitragem ou pelas normas da instituição arbitral aceita pelas partes, salvo se o processo tiver como parte a Administração Pública, já que aplicável o princípio da publicidade, previsto no art. 37, caput, da CRFB/88 (LUCIANA NARDI, 2006, p. 1-12), reafirmado pelo art. $2^{\circ}$, § $3^{\circ}$ da Lei de arbitragem, sob pena de nulidade ${ }^{20}$.

A Lei $\mathrm{n}^{\mathrm{o}}$ 9.307/96 não prevê expressamente a confidencialidade como regra obrigatória, mas no rol dos deveres dos árbitros, o art. $13, \S 6^{\circ}$, institui que o árbitro, no desempenho de sua função, deverá proceder com imparcialidade, independência, competência, diligência e discrição. Também o art. 189, IV do Código de Processo Civil de 2015 prevê o segredo de justiça em processos que versem sobre arbitragem, inclusive sobre o cumprimento de carta arbitral, desde que a confidencialidade estipulada na arbitragem seja comprovada perante o juízo ${ }^{21}$.

Contudo, na prática, verifica-se que a confidencialidade é regra nas arbitragens, diante de previsão no regulamento de arbitragem da instituição escolhida ou mediante disposição expressa na cláusula compromissória. Dentre as instituições arbitrais brasileiras que contém previsão expressa da confidencialidade do procedimento arbitral, cita-se exemplificativamente: o art. $4^{\mathrm{o}}$, VII das regras da CAMES (2017), o art. 14 das regras da CAM-CCBC (2012); o art. 10 e 20.1 das regras (AMCHAM BRASIL, 2018); o art. 13.1 das regras da CAMARB (2019); e os arts. 46 e 47 das regras da FGV Câmara de Mediação e Arbitragem (2016). No exterior também a confidencialidade é regra no procedimento arbitral, pretexta-se exemplificativamente: $o$ art. $6^{\circ}$ do Estatuto da ICC (2017), o art. 37 do regulamento das arbitragens internacionais da ICDR (2014), o braço internacional da AAA, e o art. 30 do regulamento da LCIA (2014).

Não obstante, as partes poderão afastar a confidencialidade (MONTORO, 2010), mas estarão sujeitas a acesso a segredos empresariais, eventuais de defeitos de produtos ou serviços, aspectos contábeis, o que não se recomenda, conforme doutrina de Candido Rangel Dinamarco citando Carnelutti: "não sem uma gota de cinismo, também se aponta entre as vantagens da arbitragem a defesa contra possíveis riscos fiscais da publicidade dos negócios e da contabilidade das partes" (CARNELUTTI apud DINAMARCO, 2013, p. 32).

Como se vê, vi) Redução de custos: comparada à prestação jurisdicional, a arbitragem 20 "Revela-se atentatório aos preceitos constitucionais o estabelecimento de cláusula na qual se exige o sigilo na arbitragem, não podendo o Município a ela se submeter ante a indisponibilidade do direito em discussão, traduzindo um atentado à soberania quedar-se o componente da Federação, genuflexo, às leis alienígenas" (RIO DE JANEIRO, 2003).

21 "Conflito de competência entre juízo estatal e arbitral. Pedido de tramitação sob segredo de justiça. Necessidade de comprovação da contratação de confidencialidade no procedimento arbitral, na forma exigida pelo art. 189, IV, do CPC/2015" (BRASIL, 2017a). "Cumprimento de carta arbitral. Comprovação de que o procedimento arbitral é confidencial. Aplicação do segredo de justiça ao processamento da carta arbitral” (SÃO PAULO, 2016a). "Ação de nulidade de sentença arbitral. Tramitação sob segredo de justiça, pois comprovada a existência de cláusula confidencialidade" (SÃO PAULO, 2018). Contudo, "embora o CPC/2015 garanta o segredo de justiça para processos que versem sobre arbitragem e possuam cláusula de confidencialidade, tal garantia não se estende a determinados atos, como o protesto contra alienação de bens" (SÃO PAULO, 2016b). 
pode reduzir os custos de transação da prestação jurisdicional:

Em primeiro lugar, em razão da agilidade com que é concluída. O procedimento arbitral não está sujeito à rigidez dos processos judiciais, não se submete ao regime dos infindáveis recursos a instâncias superiores, e os árbitros, não raro, contam com a infraestrutura necessária para que suas decisões sejam tomadas com grande rapidez.

Na prestação jurisdicional estatal, o tempo de espera por uma decisão definitiva gera alto custo para as partes, que ficam privadas dos bens ou direitos litigiosos durante todos os anos que precedem o efetivo cumprimento da decisão transitada em julgado. Nesse caso, as partes arcam com o custo de oportunidade decorrente da privação dos bens e direitos disputados em Juízo (PUGLIESE; SALAMA, 2008, p. 20).

Ademais, a "maior eficiência da arbitragem na solução de disputas cria incentivos para o adimplemento das obrigações contratuais pelas partes" (PUGLIESE; SALAMA, 2008, p. 24), que não poderão contar com a demora na solução da lide, inevitável no Judiciário. Ao argumento de que os custos da arbitragem são altos, contrapomos o de que há Câmaras, como a Câmara de Mediação e Arbitragem Especializada (CAMES, 2020) que cobram valores mais próximos das custas judiciais (EUZÉBIO, 2012), viabilizando arbitragem, com sistema próprio de processo eletrônico, em prazo célere e com quadro de árbitros de excelência.

Ressalta-se que também deve ser inserido no cálculo de custos o tempo dispendido pelas partes no tratamento da questão em reuniões com advogados e demais providências, já que no Judiciário a atuação será da primeira Instância até, eventualmente, os Tribunais Superiores, com gastos de honorários e pareceres que só aumentarão, enquanto que na arbitragem a questão será resolvida em Instância única. Inclusive estão em jogo os custos de oportunidade ${ }^{22}$, sobre o tema discorre a doutrina (TIMM; GUANDALINI; RICHTER, 2017):

O custo de oportunidade da não escolha da arbitragem é em parte formado pela grande demora na alocação dos direitos de propriedade, o qual parece ser a utilidade que a propriedade poderia ter proporcionado ao titular do direito pela diferença entre o tempo da prolação da sentença arbitral (anterior) e o trânsito em julgado da decisão judicial (posterior). Não por outro motivo, o custo de oportunidade ao se não adotar arbitragem é evidente quando se sabe, ao menos quando a não opção leva ao judiciário brasileiro, que a demora na alocação da propriedade será presumidamente mais longa.

Em poucas palavras, o custo de oportunidade leva em consideração o tempo em que o valor em litígio ficará imobilizado em virtude da demora da duração da solução da lide. Conclui a doutrina que "assim, ao deixar-se de adotar arbitragem, o custo de oportunidade aumenta claramente com a possibilidade de se poder escolher um julgador em tese mais especializado, sem

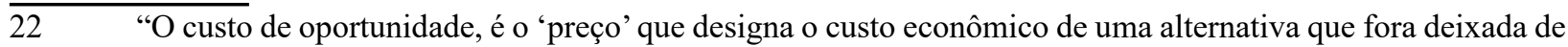
lado, que fora preterida, ou seja, o custo de alocação alternativa daquele recurso escasso" (TIMM; GUANDALINI; RICHTER, 2017). 
as limitações apresentadas pelo Judiciário” (TIMM; GUANDALINI; RICHTER, 2017).

Portanto, considera-se ao final que o sistema arbitral tem por finalidade resolver as situações de divergência contratual em tempo suficiente à reparação de outros créditos o favorecendo frente ao sistema tradicional e permite o tratamento adequado dos conflitos de forma a conceder maior segurança jurídica ao empresariado envolvido (DIAS, 2018, p. 295).

Não se podendo desconsiderar ainda a hipótese de vii) Adequação do procedimento para transações internacionais: na qual Roberto Nussinkis Mac Cracken (2014, p. 120) destaca que "O fato de a arbitragem comercial internacional ter sido criada e evoluída especificamente para tratar de conflitos necessariamente entre partes privadas de Estados distintos também é atrativo para o investidor estrangeiro". Essa adequação do procedimento poderá vir a estimular o investidor estrangeiro a investir no Brasil, sabendo que no caso de conflito poderá evitar os procedimentos estabelecidos para a resolução dos conflitos internos. Em eventual conflito entre um investidor estrangeiro e uma empresa brasileira, não se cogita que o procedimento adotado pelos tribunais brasileiros, criados com a intenção de resolver conflitos entre partes brasileira, seja o mais adequado para resolver a disputa. Nesse contexto, surge a arbitragem comercial internacional que foi desenvolvida exclusivamente para esse fim e considera as diferenças legais, políticas e culturais das partes envolvidas, proporcionando muito mais segurança jurídica ao investidor de fora do país (CRACKEN, 2014, p. 121).

Nem há que se desconsiderar o viii) caráter final e vinculante da sentença proferida pelo(s) árbitro(s $)^{23}$ : decorre da mencionada natureza jurisdicional da arbitragem, fazendo a sentença arbitral coisa julgada material e não se sujeitando a recurso ou a homologação pelo Poder Judiciário. Inexiste a previsão de recursos na Lei de Arbitragem, com exceção da possibilidade do pedido de correção de erro material ou de esclarecimento de omissão ${ }^{24}$, o que seria equivalente aos embargos de declaração na esfera judicial. Eventual pedido de correção deve ser deduzido no prazo de cinco dias do recebimento da notificação de sentença arbitral (art. 30 da Lei de Arbitragem).

No âmbito internacional, nos países desenvolvidos, a possibilidade de revisão da sentença arbitral estaria adstrita às questões de equidade processual, de jurisdição e de ordem pública. Seria praticamente nulo o fundamento legal que permitisse que a sentença arbitral fosse analisada nos tribunais estatais sob o argumento de que a decisão dos árbitros foi equivocada (CRACKEN, 2014, p. 121). Nesse sentido, Roberto Nussinkis Mac Cracken (2014, p. 122-123) acentua que o caráter final da sentença arbitral distingue a arbitragem da mediação e de outros métodos de solução de conflitos que não são vinculantes. A vinculação das partes à sentença arbitral confere maior segurança ao investidor estrangeiro, considerando que garante que a decisão proferida pelos especialistas será final e que as partes estarão a ela vinculadas. Ademais, a irrecorribilidade impede

$\overline{23} \quad$ Nas Ordenações Filipinas havia a possibilidade de recurso aos juízes ordinários, funcionando o Poder Judiciário como uma espécie de segunda instância da arbitragem.

24 "Art. 30. No prazo de 5 (cinco) dias, a contar do recebimento da notificação ou da ciência pessoal da sentença arbitral, salvo se outro prazo for acordado entre as partes, a parte interessada, mediante comunicação à outra parte, poderá solicitar ao árbitro ou ao tribunal arbitral que:

I - corrija qualquer erro material da sentença arbitral;

II - esclareça alguma obscuridade, dúvida ou contradição da sentença arbitral, ou se pronuncie sobre ponto omitido a respeito do qual devia manifestar-se a decisão. 
que mais tempo seja gasto com eventuais julgamentos de recursos, a exemplo do que ocorre nos tribunais.

Dento da noção de execução processual sincrética do CPC/2015 tem-se, ainda, a ix) facilidade no cumprimento da sentença arbitral: Redfern e Hunter (2009, p. 520) assentam que o compromisso arbitral, bem como qualquer contrato devem possibilitar a execução do direito, sob pena de constituírem mera declaração de intenção desprovida de efeitos jurídicos. Consoante, Roberto Nussinkis Mac Cracken (2014, p. 123) destaca que a fácil execução da sentença arbitral é decorrência da Convenção de Nova Iorque, pela qual os países signatários assumem a obrigação de dar efeito às sentenças arbitrais proferidas em outros países, desde que também sejam signatários. A sentença arbitral, de acordo com o CPC, é título executivo judicial:

Art. 515. São títulos executivos judiciais, cujo cumprimento dar-se-á de acordo com os artigos previstos neste Título:

$[\ldots]$

VII - a sentença arbitral;

$[\ldots]$

Neste sentido, a certeza de que a decisão arbitral poderá ser imposta às partes e cumprida no território brasileiro constitui um outro atrativo da arbitragem comercial internacional, proporcionando segurança ao investidor estrangeiro e a aplicação de recursos em empresas brasileiras (CRACKEN, 2014, p. 124);

Por fim, a vantajosidade da x) neutralidade: permite que o tribunal arbitral funcione de maneira "desnacionalizada", permitindo que o investidor estrangeiro faça o seu investimento sem o receio de ter que submeter seus conflitos a uma corte nacional que possa parecer parcial e favorável ao indivíduo que ostenta a mesma nacionalidade do órgão julgador (CRACKEN, 2014, p. 126), afastando-se a possibilidade da adoção de medidas arbitrárias ou hostis ao capital estrangeiro.

\section{CONSIDERAÇÕES FINAIS}

É sabido que a forte presença de novos atores no âmbito dos investimentos, advindos do processo de globalização, fez surgir o clamor por respaldos jurídico e governamentais que permitissem maior segurança jurídica aos investidores, resultando inclusive na criação do International Centre for Settlement of Investment Disputes - ICSID, entidade vinculada ao Banco Mundial. O Brasil, no entanto, preferiu não aderir à Convenção de Washington, o que eventualmente pode dificultar a atração de novos investimentos estrangeiros ao país.

Em contraponto, percebe-se que nos últimos anos a sociedade brasileira tem optado por investir, reforçando a necessidade da utilização de mecanismos adequados para a solução de eventuais conflitos que venham a surgir. Vale ressaltar que o judiciário brasileiro se encontra assoberbado e não conseguirá atender às expectativas dos investidores e às necessidades do 
mercado. Bem por isso, destacou-se durante a maior parte deste trabalho a relevância social, econômica e jurídica da arbitragem como meio adequado de resolução de conflitos na área de investimentos.

Dentre todas as vantagens apresentadas, frisa-se: a adequação, a especialização, a segurança jurídica, a celeridade (se comparada com as vias judiciais ordinárias), a flexibilidade procedimental (com a possibilidade de adequação do procedimento às necessidades específicas das partes, sem a obrigação de se observar prazos e procedimentos estabelecidos em lei), a confidencialidade no procedimento, de forma a resguardar o interesse das partes envolvidas, a redução e a previsão dos custos, a adequação do procedimento para transações internacionais (que apresentam suas especificidades), o caráter final e vinculante da sentença arbitral, que não se sujeita à infinidade de recursos previstos no nosso sistema processual civil que prolongam de forma imprevisível a duração do processo e trazem incerteza sobre o resultado da demanda, a maior facilidade no cumprimento das sentenças proferidas pelos árbitros, especialmente no caso de arbitragens internacionais, e a garantia da neutralidade, que nem sempre se observa em outras formas de resolução de conflitos.

Conforme se apontou, é possível a eleição da arbitragem para a resolução de qualquer conflito decorrente de contratos de investimentos envolvendo partes maiores e capazes nas relações estabelecidas entre particulares, entre particulares e o Estado ou mesmo entre Estados, qualquer que seja o tipo de investimento realizado no Brasil (direto ou indireto, nacional ou estrangeiro), devendo, no entanto, cada uma dessas situações específicas ser objeto de novos estudos que ultrapassam os limites desta pesquisa.

Considera-se, ao final, que a arbitragem de investimento representa um instrumento adequado e especializado para a solução de disputas envolvendo investimentos nacionais e estrangeiros, oferecendo a necessária segurança ao investidor que poderá escolher árbitros especializados no assunto, evitando que suas questões sejam apreciadas pelos tribunais ordinários, que muitas vezes não têm conhecimento específico sobre a matéria, constituindo mecanismo mais benéfico para a preservação dos direitos dos investidores em comparação com o processo judicial.

\section{REFERÊNCIAS}

ABBUD, André de Albuquerque Cavalcanti. Arbitragem no Brasil - Pesquisa CBAr-Ipsos. São Paulo: Comitê Brasileiro de Arbitragem - CBAr, 2012. Relatório. Disponível em: http:// www.cbar.org.br/PDF/Pesquisa_CBAr-Ipsos-final.pdf. Acesso em: 13 mar. 2020.

AMCHAM BRASIL. Arbitragem \& Mediação. Regulamento de Arbitragem. Estatuto do Centro de Arbitragem e Mediação AMCHAM. São Paulo: AMCHAM-SP, 2018. Disponível em: https:// estatico.amcham.com.br/arquivos/2018/arbitragem-comercial-regulamento.pdf. Acesso em: 13 mar. 2020.

BARBOSA, Rui. Oração aos moços. 5. ed. Rio de Janeiro: Fundação Casa de Rui Barbosa, 
1997. Disponível em: http://www.casaruibarbosa.gov.br/dados/DOC/artigos/rui_barbosa/FCRB_ RuiBarbosa_Oracao_aos_mocos.pdf. Acesso em: 10 mar. 2020.

BONIZZI, Marcelo José Magalhães; FERREIRA, Olavo Augusto Vianna Alves. Declaração de inconstitucionalidade pelo árbitro: vedação ou dever. Revista dos Tribunais Online, São Paulo, SP, v. 274, p. 543-578, dez. 2017. Disponível em: https://www.academia.edu/35242156/ artigo_REVISTA_DE_PROCESSO_CONTROLE_DE_CONSTITUCIONALIDADE_PELO_ ÁRBITRO.pdf. Acesso em: 9 mar. 2020.

BORN, Gary B. Internacional commercial arbitration. Alphen aan den Rijn, Zuid-Holland: Kluwer Law Internacional, 2009.

BRASIL. [Constituição (1988)]. Constituição da República Federativa do Brasil de 1988.

Brasília: Presidência da República, [2016]. Disponível em: http://www.planalto.gov.br/ccivil_03/ constituicao/constituicao.htm. Acesso em: 13 mar. 2020.

BRASIL. Lei $\mathbf{n}^{\mathbf{0}}$ 14.133, de $1^{\mathbf{0}}$ de abril de 2021. Lei de Licitações e Contratos Administrativos. Brasília, DF: Presidência da República, 2021. Disponível em: http://www.planalto.gov.br/ ccivil_03/_ato2019-2022/2021/lei/L14133.htm. Acesso em: 13 mar. 2020.

BRASIL. Superior Tribunal de Justiça. Decisão monocrática Conflito de Competência 151.130/SP. Decisão reconsiderada pela PET. Relatora: Ministra Nancy Andrighi. Brasília, 9 mar. 2017a.

BRASIL. Superior Tribunal de Justiça. REsp 1.383.776/AM. Segunda Turma. Relator: Og Fernandes. Brasília, 17 set. 2018a.

BRASIL. Superior Tribunal de Justiça. REsp 1.614.070/SP. Terceira Turma. Relatora: Ministra Nancy Andrighi. Brasília, 29 jun. 2018 b.

BRASIL. Superior Tribunal de Justiça. REsp 1.636.102/SP. Terceira Turma. Relator: Ricardo Villas Bôas Cueva. Brasília, 1 out. 2017 b.

CAHALI, Francisco José. Curso de arbitragem. Mediação. Conciliação. Resolução CNJ 125/2010. São Paulo: Editora Revista dos Tribunais, 2017.

CÂMARA, Alexandre Freitas. Arbitragem: Lei n 9.307/96. 2. ed. Rio de Janeiro: Lumen Juris, 1997.

CAMARB- Câmara de Mediação e Arbitragem Empresarial - Brasil. Regulamento de arbitragem. São Paulo: CAMARB, 2019. Disponível em: http://camarb.com.br/arbitragem/ regulamento-de-arbitragem/. Acesso em: 13 mar. 2020.

CAM-CCBC - Centro de Arbitragem e Mediação da Câmara de Comércio Brasil-Canadá. Regulamento de Arbitragem 2012. São Paulo: CAM-CCBC, 2012. Disponível em: https:// ccbc.org.br/cam-ccbc-centro-arbitragem-mediacao/resolucao-de-disputas/arbitragem/ regulamento-2012/. Acesso em: 13 mar. 2020.

CAMES - Câmara de Mediação e Arbitragem Especializada. Arbitragem. São Paulo: CAMESBrasil, 2020. Disponível em: https://www.camesbrasil.com.br/arbitragem/. Acesso em: 13 mar. 2020. 
CAMES-Câmara de Mediação e Arbitragem Especializada Regulamento arbitragem. São Paulo: CAMES-Brasil, 2017. Disponível em: https://www.camesbrasil.com.br/arbitragem/ regulamento-arbitragem/. Acesso em: 13 mar. 2020.

CARVALHO, Getúlio. Mu1tinacionais: os limites da soberania. 4. ed. Rio de Janeiro: Fundação Getúlio Vargas, 1982.

CHACEL, Julian; LOSS, Juliana. A gestão extrajudicial de disputas e o tempo. Cadernos FGV Projetos, Rio de Janeiro, RJ, ano 12, n. 30, p. 32-36, abr./maio, 2017.

CONSELHO NACIONAL DE JUSTIÇA. Coordenadoria de Imprensa. Justiça em números 2019: sumário executivo. Brasília: Imprensa CNJ, 2019. Disponível em: https://www.cnj.jus. br/wp-content/uploads/conteudo/arquivo/2019/08/8ee6903750bb4361b5d0d1932ec6632e.pdf/. Acesso em: 03 mar. 2020.

CONSELHO NACIONAL DE JUSTIÇA. Secretaria de Comunicação. Justiça em números 2017: destaques. Brasília: Imprensa CNJ, 2017. Disponível em: https://www.cnj.jus.br/wpcontent/uploads/2019/08/e5b5789fe59c137d43506b2e4ec4ed67.pdf. Acesso em: 3 mar. 2020.

CORREAA, Cristiane Sanches de Souza. Os regimes de investimento direto estrangeiro no Brasil: regulação e política externa nacional. 2007. 270 f. Dissertação (Mestrado em Relações Internacionais) - Universidade Federal de Santa Catarina, Florianópolis, SC, 2007. Disponível em: http://www.athena.biblioteca.unesp.br/exlibris/bd/cathedra/08-07-2015/000742078.pdf. Acesso em: 9 set. 2021.

COSTA, Larissa Maria Lima. A arbitragem do Centro Internacional de Resolução de Disputas sobre Investimentos (CIRDI): uma análise sobre a autonomia do consentimento dos Estados. 2006. 224 f. Dissertação (Mestrado em Direito) - Universidade Federal de Santa Catarina, Florianópolis, SC, 2006. Disponível em: https://repositorio.ufsc.br/xmlui/bitstream/ handle/123456789/88365/228127.pdf?sequence=1\&isAllowed=y. Acesso em: 9 set. 2021.

COTIAS, Adriana. Volume aplicado por pessoa física atinge R\$ 3,1 trilhões, mostra Anbima: cifra representa alta de 8,4\% no acumulado. Valor Econômico, São Paulo, 18 nov. 2019. Disponível em: https:/valor.globo.com/financas/noticia/2019/11/18/volume-aplicado-por-pessoafsica-atinge-r-31-trilhes-mostra-anbima.ghtml. Acesso em: 2 mar. 2020.

CRACKEN, Roberto Nussinkis Mac. Arbitragem no investimento estrangeiro: segurança jurídica. 2014. 269 f. Tese (Doutorado em Direito) - Pontifícia Universidade Católica de São Paulo, São Paulo, SP, 2014. Disponível em: https://tede2.pucsp.br/bitstream/handle/6646/1/ Roberto\%20Nussinkis\%20Mac\%20Cracken.pdf. Acesso em: 29 fev. 2020.

CREMASCO, Suzana Santi; BENTO, Daniel Freitas Drumond; FIORAVANTE, Leonardo Sette Abrantes. A alegação de existência da convenção de arbitragem antes da contestação no CPC/2015. In: DIDIER JÚNIOR, Fredie; ZANETI JÚNIOR, Hermes; CABRAL, Trícia Navarro Xavier (org.). Justiça multiportas: mediação, conciliação, arbitragem e outros meios adequados de solução de conflitos. 2. ed. Salvador: JusPodivm, 2018. v. 1, p. 855-872.

DIAS, Feliciano Alcides. Análise econômica da arbitragem. Rio de Janeiro: Lumen Juris, 2018. 
DIDIER JÚNIOR, Fredie; ZANETI JÚNIOR, Hermes. Justiça multiportas e tutela adequada em litígios complexos: a autocomposição e os direitos coletivos. In: ZANETI JÚNIOR, Hermes; CABRAL, Trícia Navarro Xavier (coord.). Justiça multiportas: mediação, conciliação, arbitragem e outros meios adequados de solução de conflitos. 2. ed. Salvador: Juspodivm, 2018. p. 35-66.

DINAMARCO, Cândido Rangel. Arbitragem na teoria geral do processo. São Paulo: Malheiros, 2013.

EUZÉBIO, Gilson Luiz. Projeto prevê até 6\% para custas judiciais. Agência CNJ de Notícias, Brasília, 2 maio 2012. Notícias CNJ. Disponível em: https:/www.cnj.jus.br/projeto-preve-ate-6para-custas-judiciais/. Acesso em: 13 mar. 2020.

FERNANDES, Waleiska. Morosidade processual corresponde a 50\% das demandas na Ouvidoria do CNJ. Agência CNJ de Notícias, Brasília, 10 dez. 2015. Notícias CNJ. Disponível em: https:// www.cnj.jus.br/morosidade-processual-corresponde-a-50-das-demandas-na-ouvidoria-do-cnj/. Acesso em: 2 mar. 2020.

FERREIRA, Olavo Augusto Vianna Alves; ROCHA, Matheus Lins; FERREIRA, Débora Cristina Fernandes Ananias Alves. Lei de arbitragem: comentada artigo por artigo. São Paulo: Juspodivm, 2019.

FGV CÂMARA DE MEDIAÇÃO E ARBITRAGEM. Regulamento de arbitragem. Versão de 2016 (vigente). Rio de Janeiro, RJ, Câmara FGV, 2016. Disponível em: https:/camara.fgv.br/ conteudo/regulamento-da-camara-fgv-de-mediacao-e-arbitragem. Acesso em: 3 mar. 2020.

GIUSTI, Gilberto; TRINDADE, Adriano Drummond C. As arbitragens internacionais relacionadas a investimentos: a convenção de Washington, o ICSID e a posição do Brasil.

Revista de Arbitragem e Mediação, Brasília, DF, v. 7, p. 49-78, out./dez. 2005. Disponível em: https://www.revistadostribunais.com.br/maf/app/resultList/t?\&src=rl\&srguid=i0ad6adc60000017 087cc766d4074d382\&docguid=Iab7da5f0f25311dfab6f010000000000\&hitguid=Iab7da5f0f 253 $11 \mathrm{dfab} 6 \mathrm{f} 010000000000 \&$ spos $=1 \&$ epos $=1 \& \mathrm{td}=618 \&$ context $=8 \&$ crumb-action $=$ append $\&$ crumblabel=Documento\&isDocFG=true\&isFromMultiSumm=true\&startChunk=1\&endChunk=1. Acesso em: 27 fev. 2020.

GUIMARÃES, Samuel Pinheiro. Capital nacional e capital estrangeiro. Estudos Avançados, São Paulo, SP, v. 14, n. 39, p. 143-160, 2000. Disponível em: https://doi.org/10.1590/S010340142000000200011. Acesso em: 9 set. 2021.

HERNANDES NETO, Antonio Marcos. Arbitragem em investimento estrangeiro e o ICSID. 2011. 150 f. Dissertação (Mestrado em Direito das Relações Econômicas Internacionais) Pontifícia Universidade Católica de São Paulo, São Paulo, SP, 2011. Disponível em: https:// sapientia.pucsp.br/handle/handle/5529. Acesso em: 29 fev. 2020.

ICC - International Chamber of Commerce. Arbitration rules. Paris, France: ICC, 2017. Disponível em: https://iccwbo.org/dispute-resolution-services/arbitration/rules-of-arbitration/. Acesso em: 3 mar. 2020.

ICDR - International Centre for Dispute Resolution. Procedimentos para a resolução de disputas internacionais. Nootdorp: ICDR, 2014. Disponível em: https://www.adr.org/sites/ 
default/files/International\%20Dispute\%20Resolution\%20Procedures\%20\%28Including\%20 Mediation\%20and\%20Arbitration\%20Rules\%29\%20-\%20Portuguese.pdf. Acesso em: 13 mar. 2020.

LCIA. Arbitration rules. London: LCIA, 2014. Disponível em: http://www.lcia.org/Dispute Resolution_Services/lcia-arbitration-rules-2014.aspx\#Article\%2030. Acesso em: 13 mar. 2020.

LEMES, Selma Ferreira. Arbitragem. Princípios jurídicos fundamentais. Direito brasileiro e comparado. Revista dos Tribunais, São Paulo, v. 686/1992, p. 73-89, dez. 1992.

LEW, Julian D. M.; MISTELIS, Loukas A.; KRÖLL, Stefan Michael. Comparative Internacional Arbitration. Alphen aan den Rijn, Zuid-Holland: Kluwer Law Internacional, 2003.

MARTÍNEZ, José Maria Roca. Arbitraje e instituciones arbitrales. Barcelona: J. M. Bosch Ed., 1992.

MONTENEGRO Manuel Carlos. Morosidade da justiça e a principal reclamação recebida pela ouvidoria do CNJ. Agência CNJ de Notícias, Brasília, 1 out. 2014. Notícias CNJ. Disponível em: https://www.cnj.jus.br/morosidade-da-justica-e-a-principal-reclamacao-recebida-pelaouvidoria-do-cnj/. Acesso em: 2 mar. 2020.

MONTENEGRO, Manuel Carlos. Estatísticas mostram evolução do combate à morosidade na Justiça. Agência CNJ de Notícias, Brasília, 4 set. 2017. Notícias CNJ. Disponível em: https:// www.cnj.jus.br/estatisticas-mostram-evolucao-do-combate-a-morosidade-na-justica/. Acesso em: 3 mar. 2020.

MONTORO, Marcos André Franco. Flexibilidade do procedimento arbitral. 2010. $415 \mathrm{f}$. Tese (Doutorado em Direito) - Universidade de São Paulo, São Paulo, SP, 2010. Disponível em: https://www.teses.usp.br/teses/disponiveis/2/2137/tde-16082011-161411/pt-br.php. Acesso em: 13 mar. 2020.

MUNIZ, Joaquim de Paiva. Guia politicamente incorreto da arbitragem brasileira: visão crítica de vinte anos de sucesso. Revista de Arbitragem e Mediação, Brasília, DF, v. 50, 2016. Disponível em: http://www.mpsp.mp.br/portal/page/portal/documentacao_e_divulgacao/ doc_biblioteca/bibli_servicos_produtos/bibli_boletim/bibli_bol_2006/RArbMed_n.50.14.PDF. Acesso em: 13 mar. 2020.

NALINI, José Renato. É urgente construir alternativas à justiça. In: ZANETI JÚNIOR, Hermes; CABRAL, Trícia Navarro Xavier (coord.). Justiça multiportas: mediação, conciliação, arbitragem e outros meios adequados de solução de conflitos. 2. ed. Salvador: JusPodivm, 2018. p. 27-34.

PONTES, Felipe. Palácio Guanabara é da União, decide STJ na ação mais antiga do país: processo ainda pode continuar se houver recurso da família imperial. Agência Brasil, Brasília, DF, 6 dez. 2018. Disponível em: https://agenciabrasil.ebc.com.br/justica/noticia/2018-12/palacioguanabara-e-da-uniao-decide-stj-na-acao-mais-antiga-do-pais. Acesso em: 9 mar. 2020.

PUGLIESE, Antonio Celso Fonseca; SALAMA, Bruno Meyerhof. A economia da arbitragem. Escolha racional e geração de valor. Revista Direito GV, São Paulo, v. 4, p. 15-27, jan./jun. 
2008.

REDFERN, Alan; HUNTER, J. Martin H. International arbitration. Oxford: Oxford University Press, 2009.

RIO DE JANEIRO (Estado). Tribunal de Justiça. AI 0005615-64.2003.8.19.0000. 13 ${ }^{\text {a }}$ Câmara de Direito Privado. Relator: Ademir Paulo Pimentel. Rio de Janeiro, 29 out. 2003.

SALAMA, Bruno Meyerhof. Análise econômica da arbitragem. In: TIMM, Luciano Benetti (org.). Direito e economia no Brasil. São Paulo: Atlas, 2012. p. 384-389.

SALOMÃO, Luis Felipe. A atualização da lei de arbitragem. 2014. Disponível em: https:// www.migalhas.com.br/depeso/211461/a-atualizacao-da-lei-de-arbitragem. Acesso em: 05 mar. 2020.

SÃO PAULO (Estado). Tribunal de Justiça. AI 2025056-45.2016.8.26.0000. $1^{\text {a }}$ Câmara Reservada de Direito Empresarial. Relator: Hamid Bdine. São Paulo, 17 jun. 2016a.

SÃO PAULO (Estado). Tribunal de Justiça. AI 2040522-11.2018.8.26.0000. $2^{\text {a }}$ Câmara Reservada de Direito Empresarial. Relator: Grava Brasil. São Paulo, 23 maio 2018.

SÃO PAULO (Estado). Tribunal de Justiça. AI 2051878-71.2016.8.26.0000. 1 ${ }^{\text {a }}$. Câmara Reservada de Direito Empresarial. Relator: Hamid Bdine. São Paulo, 28 abr. 2016b.

SPMOST. Investimentos estrangeiros diretos e em carteira. Investimentos diretos e em portfólio: quais são as diferenças? Investimentos diretos e indiretos: essência, formas e princípios. 2021. Disponível em: https://spmost.ru/pt/procenty/pryamye-i-portfelnyeinostrannye-investicii-pryamye-i-portfelnye/. Acesso em: 8 set. 2021.

TIMM, Luciano Benetti; GUANDALINI, Bruno; RICHTER, Marcelo de Souza. Reflexões sobre uma análise econômica da ideia de arbitragem no Brasil. 2017. Disponível em: https:// www.researchgate.net/publication/321165153_REFLEXOES_SOBRE_UMA_ANALISE_ ECONOMICA_DA_IDEIA_DE_ARBITRAGEM_NO_BRASIL. Acesso em: 12 fev. $201 \overline{9}$.

VILELA, Pedro Rafael. Brasil volta a ficar entre os mais bem avaliados em ranking global: Brasil é o $22^{\circ}$ país que mais atrai investimentos estrangeiros. Agência Brasil, Brasília, 16 jun. 2020. Economia-Notícia. Disponível em: https://agenciabrasil.ebc.com.br/economia/ noticia/2020-06/Brasil-volta-a-ficar-entre-os-mais-bem-avaliados-em-ranking-global. Acesso em: 10 set. 2021.

WALD, Arnoldo. Uma nova visão dos tratados de proteção de investimento e da arbitragem internacional. Revista de Arbitragem e Mediação, Brasília, DF, v. 21, p. 9-29, abr./jun. 2009. Disponível em: https://www.revistadostribunais.com.br/maf/app/resultList/t?\&src=rl\&srguid=i 0ad82d9a000001708ce2d073f5d5574a\&docguid=I6580d1202d4111e0baf30000855dd350\&hit guid $=\mathrm{I} 6580 \mathrm{~d} 1202 \mathrm{~d} 4111 \mathrm{e} 0 \mathrm{baf} 30000855 \mathrm{dd} 350 \&$ spos $=2 \&$ epos $=2 \& \mathrm{td}=967 \&$ context $=5 \& \mathrm{crumb}-$ action $=$ append\&crumb-label=Documento\&isDocFG=true\&isFromMultiSumm=true\&startChunk $=1 \&$ endChunk=1. Acesso em: 28 fev. 2020 .

Como citar: NUNES, Danilo Henrique; MONTES NETTO, Carlos Eduardo Montes; FERREIRA, Olavo Augusto Vianna Alves. A utilização da arbitragem para os contratos de investimento no brasil: 
vantagens em relação ao procedimento judicial. Scientia luris, Londrina, v. 25, n. 3, p. 71-91, nov. 2021. DOI: $10.5433 / 21788189.2021 v 25 n 3 p 71$. ISSN: 2178-8189.

Recebido em 2020-12-27

Aprovado em 2021-09-12 